\section{Selecting a way forward}

Susie Sanderson

Chair, BDA Executive Board
Send your comments to the

Editor-in-Chief,

British Dental Journal

64 Wimpole Street,

London

W1G 8YS

Emailbdj@bda.org
I didn't sleep much the night before. There was a lot going round in my mind. Huge responsibility. I needed more information at my finger tips than I'd had to have in my head for finals. Could I remember the relevant figures? Crucial not to mislead.

And that just about sums up the emotions of the responsibility and privilege of giving evidence in person to the Commons Health Select Committee. After more than two years of lobbying from the BDA and others for parliament to give critical attention to the new dental contract, the very influential Select Committee has recognised the level of concern and is holding an inquiry. As I write, the last official oral evidence session has just finished with the Department of Health being given the opportunity to respond to the overwhelmingly negative criticisms the Committee has heard through the last few weeks.

In between the tossing and turning during the night, I reflected on all the other occasions I have spoken in public on behalf of our members and the profession. That's now too many to count, but, thanks to the very professional work in the background of the BDA's press and parliamentary team who constantly generate and trigger media interest, journalists and researchers for radio and television programmes are usually extremely well and favourably briefed before I get to the point of entering their particular lions' dens. As a consequence, it has felt as though mauling has largely been of the simultaneously questioned civil servant or minister rather than me or the profession. The high profile interviews like those on the Today programme and the holy grail of them all, the Jeremy Vine Show, have especially given fantastic opportunities to raise awareness of the impact of the profession of the new contract and the appalling way in which it was implemented.

\section{CONTRACTING FOR SERVICES - A HUGE DISTRACTION}

And of course, I speak not only on behalf of dentists but also for our patients and the public because the two sets of stakeholders are inextricably linked. To a degree, the politics and contracting for services, whether with the government, third party funders or the patients themselves directly, are a huge distraction from the delivery of dentistry and health care as we were taught to do and that for which we entered the profession in the first place. That's certainly one of the messages we've been trying to get across at our regular meetings of the BDA's parliamentary panel. Members of the panel include the dental members of parliament and other very knowledgeable politicians who all report that their constituency correspondence continues to draw attention to people's worries and anger.

No surprise then to meet up again with some of those parliamentarians across the table at the Health Select Committee. And not to be sycophantic, it was most pleasantly clear that the members of the Committee really are engaged with the issues and had been well briefed and done their own homework. Despite that, there was still challenging pressure to get the technical and complex issues across. The new contract is supposed to deliver a simpler system, more easily understood by all and which satisfies the transparent, open and accountable value for money agenda of new NHS. It was therefore quite an experience to attempt to explain the UDA, its relationship to patient charges, its variability for all dentists even within the same practice, its lack of relation in monetary terms to the volume of dentistry delivered and its place in the market. And then it was even more of an experience to watch the penny dropping as the Committee realised how it all works - or rather fails to work.

And thank goodness, they now seem to appreciate that good dentistry cannot be provided with overhanging threats posed by the sort of reductive targets set by a pseudo-unit like the UDA. But then things are moving on. Amazing how the BDA's insistent call over the last 12 months for UDAs to be scrapped as the sole measure of activity now seems to have been the Department of Health's idea all along. Well, if it gets results, never mind. And although there seems to be a disregard for, or at best a lack of understanding of, the casualties of the new arrangements, we have recently had meetings with both the Minister and the Chief Dental Officer which have been described as constructive. We'd really like to be positive about a way forward. And there are many options which would facilitate a positive future. Although I have to be realistic about the outcome of the Select Committee's report, I want to be optimistic about its recommendations and the impact of them. Committee members certainly got the full picture, in all its uncomfortable detail, about the predicament in which so many hard-working and committed dentists find themselves, through no fault or action of their own. We will have to wait and see what conclusions the Committee will draw from this compelling evidence but once again, I know we've made the most of a high profile opportunity to speak on behalf of dentists.

DOI: $10.1038 / b d j .2008 .203$ 